\title{
Implications of LCA and LCIA choices on interpretation of results and on decision support
}

\author{
Serenella Sala ${ }^{1}$ (D) Alexis Laurent ${ }^{2} \cdot$ Marisa Vieira $^{3} \cdot$ Gert Van Hoof $^{4}$
}

Received: 14 November 2020 / Accepted: 18 November 2020 / Published online: 11 December 2020

(c) The Author(s) 2020

Life cycle interpretation is one of the four phases identified in the ISO 14040 and the ISO 14044 standards (ISO 2006a,b). The interpretation phase requires a critical assessment of the result of an LCA study, encompassing life cycle inventory (LCI) and life cycle impact assessment (LCIA) phases according to the goal and scope of the study. The importance of a proper interpretation of results of an LCA study is recognized by relevant standards, guides and research articles. The ISO 14044 specifies that interpretation comprises the following elements: (i) the identification of the significant issues based on the results of the LCI and LCIA phases of LCA; (ii) an evaluation that considers completeness, sensitivity and consistency checks; and (iii) the provision of conclusions, limitations and recommendations (ISO 2006b).

LCA is also recognised as a reference method for decision support in the policy context. For example, in the EU context, several initiatives and pilots projects are related to the European Environmental Footprint initiative (EC 2013). Moreover, LCA has been included among the methods to be adopted for supporting policy impact assessment in the EU Better Regulation toolbox (EC 2015). In this setting, robust and sound interpretation of LCA results is a must. For example, in the Product Environmental Footprint (PEF) Guide (EC 2013), it is stated

Communicated by Matthias Finkbeiner.

Serenella Sala

Serenella.sala@ec.europa.eu

1 Joint Research Centre, European Commission, Via Enrico Fermi 2749; T.P. 290, 21027 Ispra, Varese, Italy

2 Section for Quantitative Sustainability Assessment (QSA), Department of Technology, Management and Economics, Technical University of Denmark, Kgs. Lyngby, Denmark

3 PRé Sustainability, Stationsplein 121, 3818 LE Amersfoort, Netherlands

4 Umicore, Broekstraat 31, 1000 Brussel, Belgium that interpretation of the results of a PEF study serves two purposes: (i) to ensure that the performance of the PEF model corresponds to the goals and quality requirements of the study; in this sense, PEF interpretation may inform iterative improvements of the PEF model until all goals and requirements are met; and (ii) to derive robust conclusions and recommendations from the analysis, for example in support of environmental improvements.

Notwithstanding that a number of methodological guidance exist on the different steps of LCA, the interpretation phase, so far, has been little systematized. This has resulted in situations, where LCA practitioners formulate conclusions and recommendations with disregard of the uncertainties or the lack of consistency underlying within the LCIA steps and across the goal and scope definition or the LCI phases. The lack of comprehensive guidance for the interpretation phase is alarming as LCA is being increasingly recognised by various private and public stakeholders as a key element for decision support. Companies are applying LCA strategically to identify sustainability improvements ranging from single case studies to product portfolio decisions (Stewart et al. 2018). Critical issues span from understanding the influence of data quality and data representativeness to the proper use of spatial and temporal differentiation in LCI and LCIA, use of normalisation and weighting, integration of novel approaches (e.g. absolute sustainability concept), consistency across LCI and LCIA, overall uncertainty assessment, sensitivity of results to different choices made in the goal and scope definition (e.g. functional unit, LCIA methodologies, LCI modelling choices, handling of multi-functional processes) and use of LCA for assessing novel technologies/products, etc.

Initially, it was recognized that interpretation was not one of the hot topics in literature studies (Heijungs et al. 2001), and authors provided numerical techniques for interpretation. Other authors, such as Gaudreault et al. (2009), while recognizing that LCA has become an important methodology for more sustainable process design, observed that its application in a decision-making context has been limited by a poor 
Table 1 Non-exhaustive list of potentially relevant issues to be considered in the interpretation phase

\begin{tabular}{ll}
\hline Linked life cyle phase & Issues to be considered in the interpretation phase \\
\hline Goal and scope & $\begin{array}{l}\text { The goal and scope phase includes several issues that may influence the interpretation of the results, such as, e.g. } \\
\text { choice of functional unit, delimitation of system boundaries (inclusion/exclusion of influential processes), selected } \\
\text { type of LCI modelling approach, handling of multi-functional processes, allocation principles. In this step there is } \\
\text { as well the selection of LCIA methodologies, which could be associated with different levels of robustness in the } \\
\text { characterisation models and indicators (see e.g. EC-JRC, 2011, for details on the evaluation criteria and the associ- } \\
\text { ated robustness factors) }\end{array}$
\end{tabular}

Life cycle inventory Use of company-specific data, particularly for activities with high impact contributions, is key. However, this is not always collected or collected only to some extent

Selection of secondary data can have a strong influence on the final LCIA results (Corrado et al. 2018). Differences can derive mainly from the system boundaries and the modelling approach adopted by the database developers

The selection of process—-based or input output—based inventories requires to fully understand and intepret the results in lihgt of the specificities in coverage and completeness of approaches (Beylot et al. 2020)

Implementation of inventory flows can vary among different LCA software. The use of harmonized nomenclature for inventory flows should be encouraged. In the meanwhile, practitioners should acknowledge possible differences due to the use of different software and/or libraries

Lack of representative data meeting data quality rules in frameworks such as the PEF has been shown to be a major constraint. While primary data collection is clearly desired, data quality rules should also provide guidance on how to use proxies and characterise uncertainties (Golsteijn and Vieira, 2020)

Assessment of novel and emerging technologies, often based on lab-scale data, can underestimate or overestimate the LCA results, and guidance for adapting the LCI accordingly are required (Bergenson et al. 2020). Role of regionalisation of inventories in both attributional and consequential LCA and the effect on the final results (Patouillard et al 2020)

LCI and LCIA interface Inconsistency may also occur between LCI and LCIA, leading to the need of verifying the potential discrepancies, e.g. between flows that are mapped in LCI and not in LCIA or opposite. Ideally the flow mapping should be the same across the LCI results, the sets of characterisation factors and the background inventory behind the normalisation references

LCIA

The characterisation step in the LCIA method entails several choices made usually in the gola and scope phase, including:

Choice of the LCIA method and its consequens on the results (Dekker et al. 2020)

Choice and scoping of sensitivity analyses performed

The use of marginal vs average characterisation factors (Huijbregts et al. 2011; Pfister and Bayer 2014; Boulay et al. 2020) and the additional perspective on the context-dependence of the choice based on the burden-sharing (Forin et al. 2020)

The use of spatially- and/or temporally-differentiated characterisation factors (Boulay et al. 2015) and the associated uncertainties (see e.g. the case study on Brasil in this issue, Andrade et al. 2020, de Freitas Alves et al., 2020). The use of spatially differentiated characterisation factors has a clear impact on the selection of relevant impact categories which are driven by different hotspots. As such it has been demonstrated that LCA based decision frameworks cannot simply be applied in different regions, without consideration of local aspects (Golsteijn and Vieira, 2020)

The handling of specific group of substances, e.g. inclusion or exclusion of long-term emissions that have strong influence on results for some impact categories (e.g. toxicity-related impacts)

The completness of the characterisation of inventory flows (e.g. how significant are the unmapped flows) as well as potentially important impact pathways and/or substances missing in the characterisation models

Complementarity of the impact assessment results at midpoint and endpoint levels

The overall uncertainty of characterised, normalised and/or weighted scores, resulting from the combination of uncertainties across the LCI and all the LCIA steps encompassed in the assessment

Specific technique may be needed to support interpretation, especially when benchmarking is at stake (Galindro et al. 2020)

Given their role in supporting the identification of the most important impact categories or magnitude of the impacts, Influential choices and parameters may also emerge through the normalisation and weighting steps:

The use of internal vs. external normalisation approaches (Pizzol et al. 2016)

The adoption of absolute or relative sustainability perspective in assessing the results (Bjoern et al. 2020)

The consideration of uncertainties associated with normalisation references and their influence on normalised impact results, including uncertainties in background national, regional or global inventories of pollutant emissions and resource consumptions (Benini and Sala 2016; Laurent and Hauschild 2015)

The temporal representativeness of normalisation data as many are very outdated

The identification of the role of weighting, namely how sensitive are results to the elected weighting method (Prado et al. 2020)

Epistemological uncertainty related to the definition of weighting factors (e.g. what counts and who should decide the weights). Recognising that weighting is always performed (implicitly or explicitly) in decision making (Galatola and Pant 2014), an important issue is the incommensurability and compensability among impact categories (Munda 2008) 
understanding of methodological choices and assumptions. They therefore recommended careful interpretation of results to improve the quality of the outcome (i.e. improve the decision-making process). This view is shared by authors such as Prado et al. (2014), who have identified the lack of robust methods of interpretation to support decision makers; hence, they provide a novel approach based on a multi-criteria decision analytic method (stochastic multi-attribute analysis for life cycle impact assessment (SMAA-LCIA)) which in their view should support both interpretation of results and policy makers. Van Hoof et al. (2013) explained how normalisation helps maintain a multi-indicator approach while keeping the most relevant indicators, allowing effective decision making. Finally, other authors, such as Cellura et al. (2011) and Huang et al. (2013), performed LCA of specific products and they pointed out the relevance of sensitivity analysis to strengthen the reliability of the results obtained and draw conclusions to support sector-specific guidelines. A structured approach covering the LCIA phase has been proposed (Castellani et al. 2017), highlighting the importance of a systematic sensitivity analysis of impact assessment models, normalisation and weighting set. Additionally, examples of sensitivity of results to impact assessment have been presented, e.g. with regard to resources and toxicity impacts (Rigamonti et al. 2017). Regarding normalisation and weighting steps, which are optional according to ISO standards, the study by Pizzol et al. (2016) provides an overview of approaches, strengths and limitations.

In view of addressing key challenges of interpretation, under the UN Environment Life Cycle Initiative's flagship project on Global Guidance on LCIA Indicators and Methods (GLAM) (UN 2020), a task force on interpretation was established to support the systematisation and harmonisation of this essential LCA phase. The outcome of this working group translated into a recent paper (Laurent et al. 2020), which illustrates the state of the art on the interpretation step in LCA, providing recommendations and highlighting the need for better structuring and framing this part of the assessment.

In this special issue, with mainly an LCIA angle, examples of open and emerging issues related to interpretation are reported. Among others presented in Laurent et al. (2020), those issues should be taken into account when critically assessing LCA results.

In Table 1, we report the different issues from the interpretation step, including those highlighted by the papers featuring this special issue, and the main open challenges the LCA community should address to support better interpretation of the results.
Open Access This article is licensed under a Creative Commons Attribution 4.0 International License, which permits use, sharing, adaptation, distribution and reproduction in any medium or format, as long as you give appropriate credit to the original author(s) and the source, provide a link to the Creative Commons licence, and indicate if changes were made. The images or other third party material in this article are included in the article's Creative Commons licence, unless indicated otherwise in a credit line to the material. If material is not included in the article's Creative Commons licence and your intended use is not permitted by statutory regulation or exceeds the permitted use, you will need to obtain permission directly from the copyright holder. To view a copy of this licence, visit http://creativecommons.org/licenses/by/4.0/.

\section{References}

Andrade EP, de Araújo Nunes AB, de Freitas Alves K, Ugaya CML, da Costa Alencar M, de Lima Santos T, da Silva Barros V, Pastor AV, de Figueirêdo MCB (2020) Water scarcity in Brazil: part 1regionalization of the AWARE model characterization factors.Int $\mathbf{J}$ Life Cycle Assess 1-17. https://doi.org/10.1007/s11367-019-01643-5

Benini L, Sala S (2016) Uncertainty and sensitivity analysis of normalization factors to methodological assumptions. Int J Life Cycle Assess 21(2):224-236. https://doi.org/10.1007/s11367-015-1013-5

Bergerson J, Cucurachi S, Seager TP (2020) Bringing a life cycle perspective to emerging technology development. J Ind Ecol 24(1):610. https://doi.org/10.1111/jiec.12990

Beylot A, Corrado S, Sala S (2020) Environmental impacts of European trade: interpreting results of process-based LCA and environmentally extended input-output analysis towards hotspot identification. Int J Life Cycle Assess 1-19. https://doi.org/10.1007/ s11367-019-01649-z

Bjoern A, Chandrakumar C, Boulay AM, Doka G, Fang K, Gondran N, Hauschild MZ, Kerkhof A, King H, Margni M, McLaren S, Mueller C, Owsianiak M, Peters G, Roos S, Sala S, Sanding G, Sim S, Vargas-Gonzalez M, Ryberg M (2020) Review of life-cycle based methods for absolute environmental sustainability assessment and their applications. Environ Res Lett 15(8):083001. https: //doi.org/10.1088/1748-9326/ab89d7

Boulay AM, Motoshita M, Pfister S, Bulle C, Muñoz I, Franceschini H, Margni M (2015) Analysis of water use impact assessment methods (part A): evaluation of modeling choices based on a quantitative comparison of scarcity and human health indicators. Int J Life Cycle Assess 20:139-160. https://doi.org/10.1007/s11367-014-0814-2

Boulay AM, Benini L, Sala S (2020) Marginal and non-marginal approaches in characterization: how context and scale affect the selection of an adequate characterization model. The AWARE model example. Int J Life Cycle Assess 1-13. https://doi. org/10.1007/s11367-019-01680-0

Castellani V, Sala S, Benini L (2017) Hotspots analysis and critical interpretation of food life cycle assessment studies for selecting eco-innovation options and for policy support. J Clean Prod 140:556-568. https://doi.org/10.1016/j.jclepro.2016.05.078

Cellura M, Longo S, Mistretta M (2011) Sensitivity analysis to quantify uncertainty in life cycle assessment: the case study of an Italian tile. Renew Sust Energy Rev 15(9):4697-4705. https://doi. org/10.1016/j.rser.2011.07.082

Corrado S, Castellani V, Zampori L, Sala S (2018) Systematic analysis of secondary life cycle inventories when modelling agricultural production: a case study for arable crops. J Clean Prod 172:3990 4000. https://doi.org/10.1016/j.jclepro.2017.03.179

de Alves Alves K, Andrade EP, Savioli JP, Pastor AV, de Figueirêdo MCB, Ugaya CML (2020) Water scarcity in Brazil: part 2-uncertainty 
assessment in regionalized characterization factors. Int $\mathrm{J}$ Life Cycle Assess 1-21. https://doi.org/10.1007/s11367-020-01739-3

Dekker E, Zijp MC, van de Kamp ME, Temme EHM, van Zelm R (2020) A taste of the new ReCiPe for life cycle assessment: consequences of the updated impact assessment method on food product LCAs. Int J Life Cycle Assess 1-10. https://doi.org/10.1007/s11367-019-01653-3

EC (2013) Commission Recommendation of 9 April 2013 on the use of common methods to measure and communicate the life cycle environmental performance of products and organisations, Off $\mathbf{J}$ Eur Union. 2013/179/EU. European Commission, Brussels. https: //eur-lex.europa.eu/legal-content/EN/TXT/PDF/?uri=CELEX: 32013 H0179\&from $=$ EN

EC (2015) Communication from the Commission to the European Parliament, the Council, the European Economic and Social Committee and the Committee of the Regions. Better regulation for better results - An EU agenda. COM/2015/0215. European Commission, Brussels. https://eur-lex.europa.eu/legal-content/EN/TXT/ $\mathrm{PDF} /$ ?uri=CELEX:52015DC0215\&from $=\mathrm{EN}$.

EC-JRC (2011) ILCD Handbook. Recommendations for life cycle impact assessment in the European context. European Commission-Joint Research Centre, Institute for Environment and Sustainability, Publications Office of the European Union, Luxembourg. https://doi. org/10.2788/33030

Forin S, Berger M, Finkbeiner M (2020) Comment to Marginal and non-marginal approaches in characterization: how context and scale affect the selection of an adequate characterization factor. The AWARE model example. Int J Life Cycle Assess 25:663-666. https://doi.org/10.1007/s11367-019-01726-3

Galatola M, Pant R (2014) Reply to the editorial "Product environmental footprint - breakthrough or breakdown for policy implementation of life cycle assessment?" written by Prof. Finkbeiner (Int J Life Cycle Assess 19(2), 266-271). Int J Life Cycle Assess 19:1356-1360. https: //doi.org/10.1007/s11367-014-0740-3

Galindro BM, Bey N, Olsen IS, Fries CE, Soares SR (2020) Use of data envelopment analysis to benchmark environmental product declarations-a suggested framework. Int J Life Cycle Assess 1-15. https://doi.org/10.1007/s11367-019-01639-1

Gaudreault C, Samson R, Stuart P (2009) Implications of choices and interpretation in LCA for multi-criteria process design: de-inked pulp capacity and cogeneration at a paper mill case study. J Clean Prod 17(17):1535-1546. https://doi.org/10.1016/j.jclepro.2009.07.003

Golsteijn L, Vieira M (2020) Applicability of the European Environmental Footprint (EF) methodology in Southern Mediterranean countrieslearnings and recommendations for enabling EF-compliant studies in regions outside of Europe. Int J Life Cycle Assess 1-10. https://doi. org/10.1007/s11367-019-01681-z

Heijungs R, Kleijn R (2001) Numerical approaches towards life cycle interpretation five examples. Int J Life Cycle Assess 6(3):141. https://doi.org/10.1007/BF02978732

Huang Y, Spray A, Parry T (2013) Sensitivity analysis of methodological choices in road pavement LCA. Int J Life Cycle Assess 18:93-101. https://doi.org/10.1007/s11367-012-0450-7

Huijbregts MAJ, Hellweg S, Hertwich E (2011) Do we need a paradigm shift in life cycle impact assessment? Environ Sci Technol 45(9):3833-3834. https://doi.org/10.1021/es200918b

ISO (2006a) ISO 14040. Environmental management - Life Cycle Assessment - Principles and Framework, Geneva, Switzerland
ISO (2006b) ISO 14044. Environmental management - life cycle assessment - requirements and guidelines, Geneva, Switzerland

Laurent A, Hauschild MZ (2015) Normalisation. In: Hauschild MZ, Huijbregts MAJ (eds.) Life Cycle Impact Assessment, LCA Compendium - The Complete World of Life Cycle Assessment, Springer, Dordrecht, pp 271-300. https://doi.org/10.1007/978-94-017-9744$3 \_14$

Laurent A, Weidema BP, Bare J, Liao X, Maia de Souza D, Pizzol M, Sala S, Schreiber H, Thonemann N, Verones F (2020) Methodological review and detailed guidance for the life cycle interpretation phase. J Ind Ecol 24(5):986-1003. https://doi.org/10.1111/ jiec. 13012

Munda G (2008) Social multi-criteria evaluation for a sustainable economy. Springer, Berlin

Patouillard L, Lorne D, Collet P, Bulle C, Margni M (2020) Prioritizing regionalization to enhance interpretation in consequential life cycle assessment: application to alternative transportation scenarios using partial equilibrium economic modeling. Int $\mathrm{J}$ Life Cycle Assess 1-17. https://doi.org/10.1007/s11367-020-01785-x

Pizzol M, Laurent A, Sala S, Weidema B, Verones F, Koffler C (2016) Normalisation and weighting in life cycle assessment: quo vadis? Int J Life Cycle Assess 22:853-866. https://doi.org/10.1007/s11367-016-1199-1

Pfister S, Bayer P (2014) Monthly water stress: spatially and temporally explicit consumptive water footprint of global crop production. J Clean Prod 73:52-62. https://doi.org/10.1016/j.jclepro.2013.11.031

Prado-Lopez V, Seager TP, Chester M, Laurin L, Bernardo M, Tylock S (2014) Stochastic multi-attribute analysis (SMAA) as an interpretation method for comparative life-cycle assessment (LCA). Int J Life Cycle Assess 19:405-416. https://doi.org/10.1007/s11367-013-0641-x

Prado V, Cinelli M, Ter Haar SF, Ravikumar D, Heijungs R, Guinée J, Seager TP (2020) Sensitivity to weighting in life cycle impact assessment (LCIA). Int J Life Cycle Assess 1-14. https://doi.org/10.1007/ s11367-019-01718-3

Rigamonti L, Falbo A, Zampori L, Sala S (2017) Supporting a transition towards sustainable circular economy: sensitivity analysis for the interpretation of LCA for the recovery of electric and electronic waste. Int J Life Cycle Assess 22:1278-1287. https://doi.org/10.1007/s11367016-1231-5

Stewart R, Fantke P, Bjoern A, Owsianiak M, Molin C, Hauschild MZ, Laurent A (2018) Life cycle assessment in corporate sustainability reporting: global, regional, sectoral, and company-level trends. Bus Strategy Environ 27(8):1751-1764. https://doi.org/10.1002/ bse. 2241

UN (2020) Guidance on Life Cycle Impact Assessment Indicators and Methods (GLAM). Life Cycle Initiative, United Nations Environmental Programme. https://www.lifecycleinitiative.org/category/ glam/. Accessed 31 October 2020

Van Hoof G, Vieira M, Gausman M, Weisbrod A (2013) Indicator selection in life cycle assessment to enable decision making: issues and solutions. Int J Life Cycle Assess 18:1568-1580. https: //doi.org/10.1007/s11367-013-0595-Z

Publisher's Note Springer Nature remains neutral with regard to jurisdictional claims in published maps and institutional affiliations. 